\title{
DNA hypermethylation in the normal colonic mucosa of patients with colorectal cancer
}

\author{
K Kawakami', A Ruszkiewicz², G Bennett', J Moore ${ }^{4}$, F Grieu', G Watanabe' and B lacopetta*,5 \\ 'Department of Surgery, Kanazawa University School of Medicine, Takaramachi 13-I, Kanazawa 920-864 I, Japan; '2Divisions of Tissue Pathology, \\ Institute of Medical and Veterinary Science, Frome Road, Adelaide SA 5000, Australia; ${ }^{3}$ Molecular Pathology, Institute of Medical and Veterinary Science, \\ Frome Road, Adelaide SA 5000, Australia; ${ }^{4}$ Colorectal Unit, Royal Adelaide Hospital, Adelaide SA 5000, Australia; ${ }^{5}$ School of Surgery and Pathology, \\ University of Western Australia, Nedlands 6009, Australia
}

The CpG-island methylator phenotype $(\mathrm{CIMP}+)$ in colorectal cancer $(\mathrm{CRC})$ is characterised by frequent hypermethylation of promoter regions in tumour suppressor genes. Low level methylation of some CpG islands is also seen in the normal colonic mucosa and increases with age; however, it is still unclear what other factors regulate this phenomenon. The first aim of our study was to determine whether the level of promoter methylation is elevated in the normal colonic mucosa of patients with $\mathrm{CIMP}^{+}$tumours. The second aim was to investigate whether common, functional polymorphisms in genes involved in methyl group metabolism are associated with the level of methylation in this tissue. CpG islands within the ER $\alpha, M Y O D, P I 6(I N K 4 A), M L H I, A P C, P I 4(A R F)$, DAPK and TIMP3 genes were quantitatively evaluated for methylation in normal colonic mucosa from a large series of CRC patients using the MethyLight assay. Genotyping was carried out for polymorphisms in the MTHFR, TS, MS, MTHFDI and DNMT3b genes. Methylation of $E R \alpha$ and MYOD in normal colonic mucosa increased with age and was higher in female subjects. Methylation of PI 6(INK4A), MLHI, TIMP3 and DAPK in normal mucosa occurred at a lower level than ER $\alpha$ and MYOD but also increased with age and was significantly higher in patients with $\mathrm{CIMP}^{+}$tumours. The DNMT3b C46359T polymorphism was associated with significantly less methylation of MYOD and MLHI and with trends for lower methylation in each of the other CpG islands examined. Our results demonstrate that age, gender and genetic factors can influence the methylation level of CpG islands in gene promoter regions of normal colonic mucosa. Further work is required to determine whether such methylation is associated with the development of $\mathrm{CIMP}^{+} \mathrm{CRC}$.

British Journal of Cancer (2006) 94, 593-598. doi: I 0.1038/sj.bjc.6602940 www.bjcancer.com

Published online 17 January 2006

(c) 2006 Cancer Research UK

Keywords: ER ; MYOD; promoter methylation; DNMT3b; polymorphism; ageing

Changes in DNA methylation patterns are frequently observed in neoplastic cells (Baylin et al, 1998). Both global hypomethylation (Feinberg and Vogelstein, 1983) and CpG-island hypermethylation (Toyota et al, 1999) occur simultaneously in colorectal cancer (CRC); however, there appears to be no relationship between these epigenetic alterations (Bariol et al, 2003). Hypermethylation of CpG islands is associated with transcriptional silencing of tumour suppressor genes including P16(INK4A) (Merlo et al, 1995) and MLH1 (Kane et al, 1997). The term CpG-island methylator phenotype $\left(\mathrm{CIMP}^{+}\right)$was proposed several years ago to describe tumours that display frequent and concurrent hypermethylation of multiple CpG islands (Toyota et al, 1999). CIMP ${ }^{+}$CRCs show characteristic clinical and pathological features that include origin in the proximal colon, higher frequency in female subjects and poorly differentiated, mucinous histology (Toyota et al, 1999; Hawkins et al, 2002; Van Rijnsoever et al, 2002). Whether these properties arise because of aberrant DNA hypermethylation or as a consequence of the microsatellite instability $\left(\mathrm{MSI}^{+}\right)$phenotype found in a high proportion of $\mathrm{CIMP}^{+}$tumours following

*Correspondence: Dr B lacopetta; E-mail: bjiac@meddent.uwa.edu.au Received I September 2005; revised 21 November 2005; accepted 2 December 2005; published online 17 January 2006 methylation-induced transcriptional silencing of $M L H 1$ has been highly contentious (Yamashita et al, 2003; Frigola et al, 2005). However, recent evidence suggests that many of the characteristic features of $\mathrm{CIMP}^{+}$tumours including poor differentiation, mucinous histology, proximal site and BRAF mutation are found independently of $\mathrm{MSI}^{+}$status (Whitehall et al, 2002; Kambara et al, 2004; Samowitz et al, 2005a, b). The $\mathrm{CIMP}^{+} / \mathrm{MSI}^{-}$tumour subgroup has worse prognosis (Ward et al, 2003; Samowitz et al, 2005b), but the overall $\mathrm{CIMP}^{+}$phenotype may be more responsive to 5-fluorouracil-based chemotherapy (Van Rijnsoever et al, 2003).

The methylation of some CpG islands in the normal colonic mucosa has been shown to increase with age (Issa et al, 1994; Ahuja et al, 1998; Nakagawa et al, 2001). This has led to a proposal by Toyota et al (1999) that methylation of some genes in this tissue is age-related (Type A genes), whereas for other genes the methylation is cancer-specific (Type $C$ genes). Examples of Type A genes include $E R \alpha$ and $M Y O D$ and for Type $C$ genes they include P16(INK4A), MLH1 and TIMP3. This classification could be misleading, however, in that age-related differences in methylation levels may be quantitative rather than qualitative. Age-related methylation and subsequent inactivation of tumour suppressor genes has been suggested as a predisposing factor for the increased risk of cancer with age (Issa, 1999). 
The factors that regulate both global DNA methylation and sitespecific hypermethylation in normal and neoplastic tissues are largely unknown. Age clearly has some influence, with dietary folate intake, alcohol consumption and gender also likely to be important factors (Choi and Mason, 2002; Kim, 2004). Genetic factors could also play a role in determining the level of normal tissue DNA methylation and hence the risk of cancer. Common, functional polymorphisms have been described for several genes involved in methyl group metabolism. Most attention has so far focused on variants of the methylenetetrahydrofolate reductase (MTHFR), thymidylate synthase (TS), methionine synthase $(M S)$, DNA methyltransferase (DNMT3b) and methylenetetrahydrofolate dehydrogenase (MTHFD1) genes (Friso et al, 2002; Paz et al, 2002; Kawakami et al, 2003; Chen et al, 2004; Sharp and Little, 2004). We previously reported the wild-type MTHFR $677 \mathrm{C}$ allele to be associated with significantly higher concentrations of two important intracellular folate intermediates compared to $677 \mathrm{~T}$ homozygous variants in CRC (Kawakami et al, 2003). These folate intermediates were present at almost twice the concentration in $\mathrm{CIMP}^{+}$compared to CIMP ${ }^{-}$tumours, suggesting that the MTHFR C677T polymorphism could also influence the level of DNA hypermethylation by altering the intracellular methyl donor pool. Work by other groups has implicated this polymorphism in the level of global DNA methylation in normal tissues (Stern et al, 2000; Friso et al, 2002; Paz et al, 2002).

In the present study, we used a quantitative assay to evaluate the methylation level in DNA from normal colonic tissue of eight CpG islands located within gene promoter regions. We were thus able to investigate for possible influences of age, gender and methyl group-related genetic factors on the level of CpG-island methylation. The finding of strong associations between high levels of normal colonic tissue methylation and the presence of $\mathrm{CIMP}^{+}$ tumours suggests that there may be a causal link.

\section{MATERIALS AND METHODS}

\section{Tissue samples}

Tissue samples from a consecutive series of 199 CRC patients undergoing elective surgery at the Colorectal Unit of the Royal Adelaide Hospital were snap frozen in liquid nitrogen within 20-40 min after resection and stored at $-70^{\circ} \mathrm{C}$. Patients had been fasted for $24 \mathrm{~h}$ prior to surgery. Samples of normal mucosa were taken as far away as possible from the tumour site and were morphologically normal in sections used to evaluate the status of that margin in routine histology. The normal sample was usually the distal resection margin for proximal colon cancers or the proximal resection margin for left colon and rectal cancers. Microsatellite instability status was determined as previously described by screening for instability at nine microsatellite loci that included both mononucleotide (BAT-25, BAT-26, BAT-40) and dinucleotide (D2S123, D10S197, D17S579, D18S34, D5S346, D17S250) repeats (Ruszkiewicz et al, 2002). Tumours showing instability at two or more loci were considered to be $\mathrm{MSI}^{+}$. Tumours showing methylation at two or more of six $\mathrm{CpG}$ islands examined (P16(INK4A), MLH1, APC, TIMP3, P14(ARF), DAPK) were classified as $\mathrm{CIMP}^{+}$(Kawakami et al, 2003). Information on patient age, gender and tumour characteristics (stage, nodal involvement, grade, mucinous histology, infiltrating lymphocytes) were obtained from the pathology report. Ethics approval for this study was received from the Sir Charles Gairdner Hospital Human Research Ethics Committee.

\section{Methylation analysis}

Aliquots of normal mucosa and tumour tissue were sent on dry ice to the Kanazawa University School of Medicine for extraction of
DNA and quantitative assessment of CpG-island methylation within the promoter regions of $E R \alpha, M Y O D, M L H 1$ (distal promoter region), P16(INK4A), TIMP3, P14(ARF), APC and DAPK. This was carried out using the MethyLight assay and oligonucleotide primer sequences described previously (Eads et al, 2001; Ishiguro et al, 2003; Kawakami et al, 2003). Briefly, tumour DNA was converted with sodium bisulphite prior to analysis of methylation using the fluorescence-based, real-time PCR MethyLight assay. The results were analysed to obtain a percentage of methylated reference (PMR) value as described previously (Eads et al, 2001). ER $\alpha, M Y O D, T I M P 3$ and DAPK were evaluated for methylation in 188 normal mucosal samples; MLH1, P16(INK4A), $p 14(A R F)$ and $A P C$ in 100 samples. These were categorised into no methylation $(\mathrm{PMR}=0)$, low methylation $(\mathrm{PMR} \leqslant$ median value of positive readings) and high methylation ( $P M R>$ median value of positive readings).

\section{Genotyping}

PCR and PCR-RFLP were used to genotype the $28 \mathrm{bp}$ tandem repeat in the enhancer region of TS and the G/C single-nucleotide polymorphism (SNP) within the triple repeat allele, respectively (Kawakami and Watanabe, 2003). The HaeIII-digested PCR product sizes were estimated using 3\% agarose gels. Genotyping for the MTHFR C677T and A1298C SNPs was carried out using PCR-F-SSCP as described earlier by our laboratory (Grieu et al, 2004). PCR-RFLP was used to genotype for SNPs in the MTHFD1 (G1958A), MS (A919G) and DNMT3b (C46359T) genes using the restriction enzymes MspI (Promega, Sydney), HaeIII (Promega) and AvrII (New England BioLabs, Brisbane), respectively, as described earlier ( $\mathrm{Paz}$ et al, 2002; Shen et al, 2002; Chen et al, 2004).

\section{Statistical analysis}

Statistical analyses were performed using the SPSS software package (Chicago, IL, USA). As methylation levels are not normally distributed, median methylation levels between different groups were compared using the Mann - Whitney $U$-test, with PMR values treated as continuous variables. Associations between age and methylation were evaluated using linear regression, while associations between methylation levels (categorised as none, low or high as described above) and clinical, pathological and genotypic features were evaluated using $\chi^{2}$ and Fishers' exact test as appropriate. All $P$-values given are two tailed with $P<0.05$ taken as statistically significant.

\section{RESULTS}

The MethyLight assay (Eads et al, 2001) was used to obtain quantitative estimates for the level of methylation of $\mathrm{CpG}$ islands within the ER $\alpha, M Y O D, P 16(I N K 4 A), M L H 1, A P C, P 14(A R F)$, $D A P K$ and TIMP3 genes in normal colonic mucosa from patients with CRC. Consistent with previous reports (Toyota et al, 1999; Rashid and Issa, 2004), $E R \alpha$ and $M Y O D$ showed high methylation levels in this tissue (Table 1). P16(INK4A), MLH1, APC, DAPK and TIMP3 each showed relatively low methylation levels in normal colonic tissue (mean PMR $<1$ ), while P14(ARF) methylation could not be detected using the MethyLight assay.

$E R \alpha$ and $M Y O D$ methylation in normal colonic tissues increased significantly with patient age $(P<0.001$ for each; Figure 1$)$. When methylation levels were categorised into none, low or high, patients with high $E R \alpha$ and MLH1 methylation were found to be significantly older than those with no methylation of these genes (Figure 2A). Patients with high P16(INK4A) and DAPK methylation also showed trends for older age. Significantly, more female subjects showed high levels of $E R \propto$ methylation relative to the no 
Table I DNA methylation level in the normal colonic mucosa of CRC patients

\begin{tabular}{lcc}
\hline CpG-island (N) & Mean PMR (range) & Median positive PMR \\
\hline ER $\alpha(188)$ & $13.3(0-99.1)$ & 12.3 \\
MYOD (I88) & $2.8(0-19.3)$ & 2.4 \\
PI6(INK4A) (I00) & $0.14(0-1.1)$ & 0.2 \\
MLHI (I00) & $0.17(0-0.9)$ & 0.3 \\
APC (I00) & $0.47(0-5.3)$ & 0.5 \\
DAPK (I88) & $0.67(0-4.5)$ & 0.6 \\
TIMP3 (I 88$)$ & $0.78(0-9.5)$ & 0.6 \\
\hline
\end{tabular}
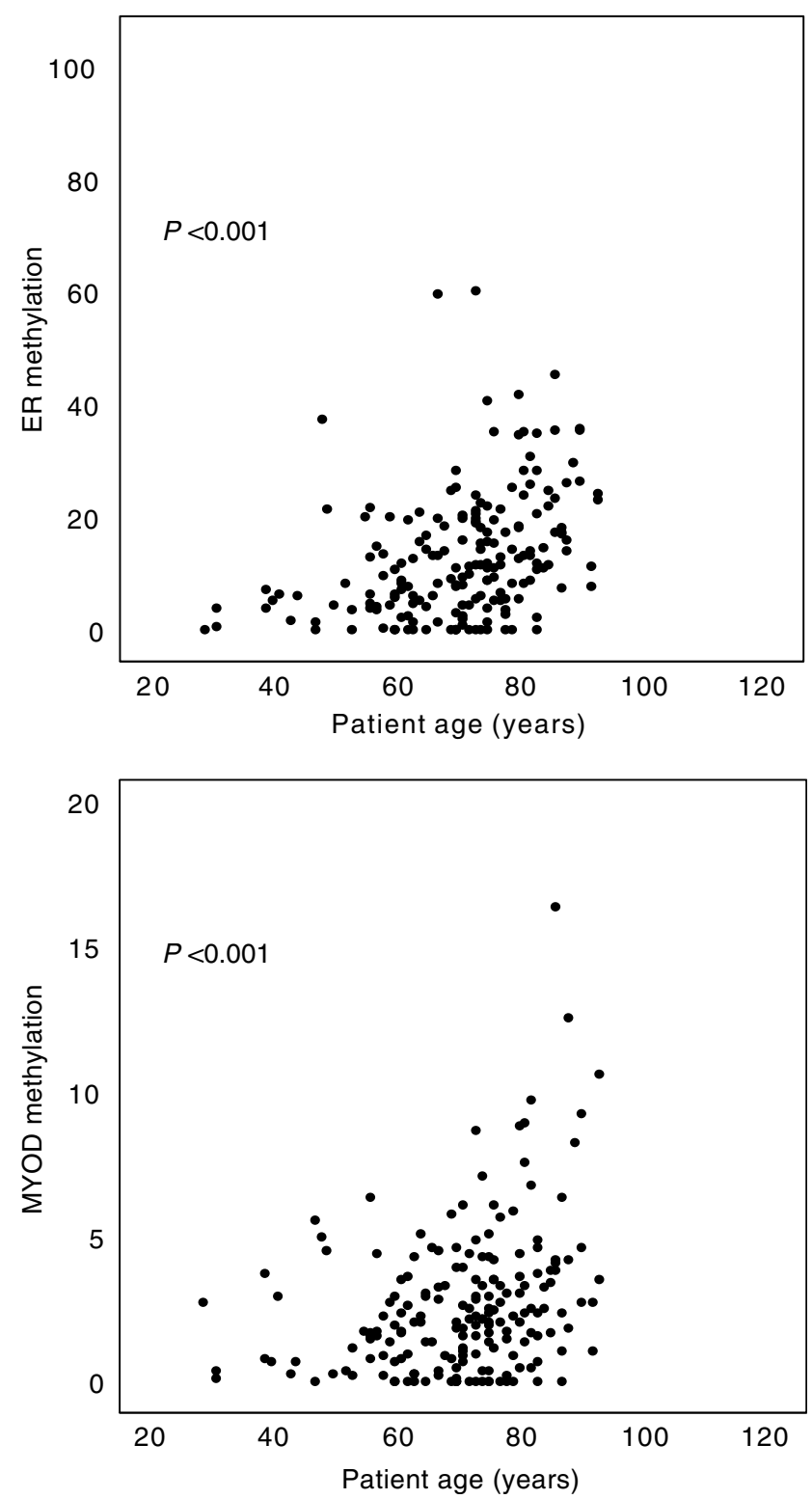

Figure I Methylation levels for $E R \alpha$ and MYOD in the normal mucosa of CRC patients in relation to age at diagnosis. Values were determined by MethyLight assay and are expressed as the percentage of a methylated reference (PMR). Older age was associated with significantly increased methylation of $E R \alpha$ and MYOD $(P<0.00 I)$.

methylation group (Figure 2B), with MYOD methylation showing the same trend. Almost half of the patients with high ER $\alpha$ methylation were female subjects compared to only $21 \%$ of those
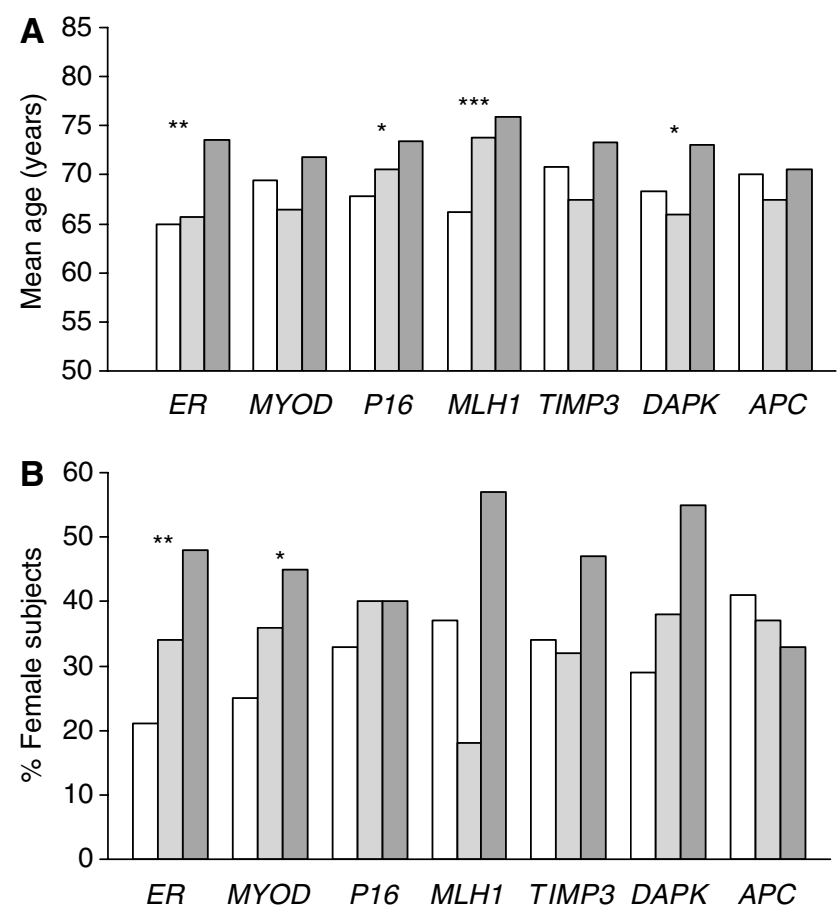

Figure 2 Methylation levels in normal colonic tissue were categorised according to no detectable methylation ( $P M R=0$; open bars), low methylation (PMR $\leqslant$ median of positive values; light bars) and high methylation (PMR > median of positive values; dark bars). A high level of methylation in normal colon tissue was associated with older age $(\mathbf{A})$ and female gender (B) compared to no detectable methylation. $* P<0$. I; *** $P<0.05$; **** $P<0.01$

with no methylation of this gene. No associations were seen between the methylation level of any gene investigated and anatomical site of the normal mucosa in the large bowel (results not shown).

Normal colonic tissue from patients with $\mathrm{MSI}^{+}$and $\mathrm{CIMP}^{+}$ tumours frequently demonstrated high methylation levels, particularly for the P16(INK4A), MLH1, TIMP3 and DAPK genes (Figure 3). High methylation levels of $M L H 1$ were seen in the normal tissue of more than one-third of patients with $\mathrm{MSI}^{+}$ tumours and just over half the patients with $\mathrm{CIMP}^{+}$tumours. Similar trends were also apparent for $E R \alpha, M Y O D$ and $A P C$. In contrast, the absence of detectable methylation for each of the genes examined in normal mucosa was observed in $<10 \%$ of patients with $\mathrm{MSI}^{+}$tumours and in $<20 \%$ of patients with $\mathrm{CIMP}^{+}$tumours. Of the $44 \mathrm{CIMP}^{+}$tumours in this cohort, 28 (64\%) were $\mathrm{MSI}^{-}$and $16(36 \%)$ were $\mathrm{MSI}^{+}$, thus allowing us to examine the $\mathrm{CIMP}^{+} / \mathrm{MSI}^{-}$tumour group separately to the $\mathrm{CIMP}^{+} / \mathrm{MSI}^{+}$group. Although the sample sizes were small, we observed higher $M L H 1$ methylation $(P=0.05)$ but lower $E R \alpha$ methylation $(P=0.025)$ in the normal mucosa of patients with $\mathrm{CIMP}^{+} / \mathrm{MSI}^{+}$tumours compared to those with $\mathrm{CIMP}^{+} / \mathrm{MSI}^{-}$ tumours. None of the other genes showed significant differences in methylation level between the two groups.

We next investigated whether common polymorphisms in the methyl group metabolism genes MS, MTHFR, MTHFD1, DNMT3b and TS were associated with the levels of CpG-island methylation in normal colonic tissue. Only the DNMT3b C46359T variant was consistently associated with altered methylation levels in normal colonic mucosa. Methylation levels of MYOD and MLH1 were both significantly lower in DNMT3b TT homozygous patients compared to the combined CC/CT group of patients (Mann-Whitney $U$-test, $P=0.027$ and $P=0.013$, respectively), with methylation in each of 

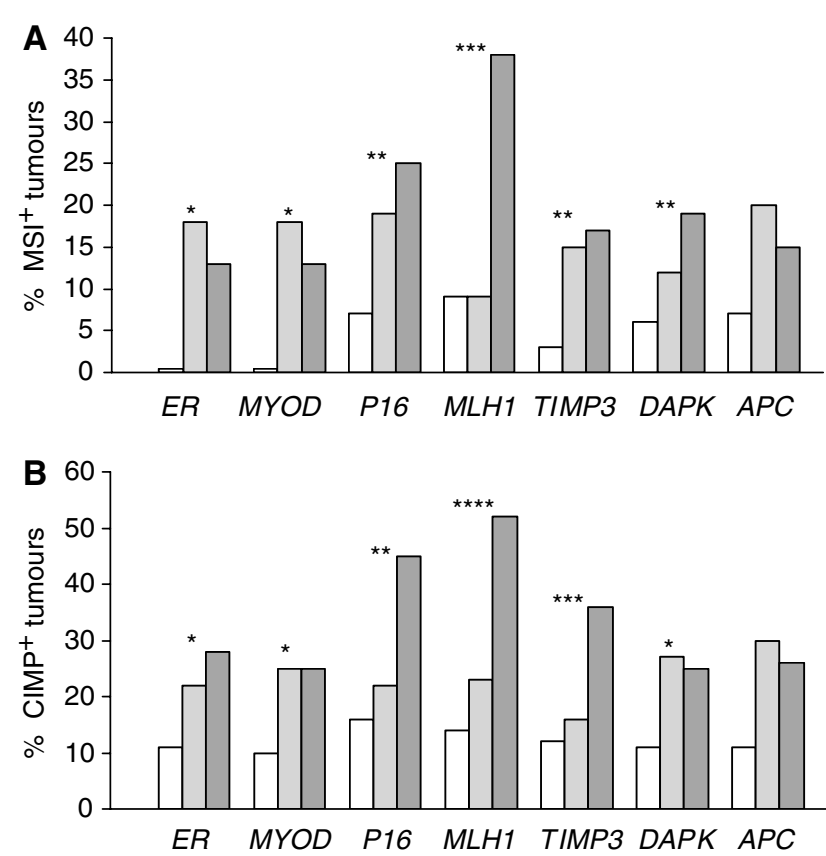

Figure 3 High methylation levels in normal colon tissue were more often associated with the presence of $\mathrm{MSI}^{+}(\mathbf{A})$ and $\mathrm{CIMP}^{+}(\mathbf{B})$ tumours compared to cases with no detectable methylation. $* P<0.1$; $* * P<0.05$ **** $P<0.0$ I; **** $P<0.00$ I. No detectable methylation (open bars), low methylation (light bars) and high methylation (dark bars) groups are shown.

the other genes showing the same trend. For each gene, the highest percentage of DNMT3b TT homozygous genotype was seen in patients who had no detectable methylation in their normal colonic mucosa (Figure 4).

\section{DISCUSSION}

Type A methylation sites were originally proposed to describe CpG islands that are methylated in normal tissue and whose methylation increases with age, with the best-known examples being $E R \alpha$ and MYOD (Toyota et al, 1999). In contrast, Type C CpG islands were proposed as being methylated exclusively in tumour tissue, with P16(INK4A) and MLH1 suggested as examples. In the present study, we used a quantitative assay to evaluate DNA methylation levels in normal colonic tissue from CRC patients who underwent surgical treatment. As expected, methylation levels for $E R \alpha$ and $M Y O D$ in normal colonic mucosa were higher than the other genes evaluated (Table 1) and increased with age (Figure 1). However, we obtained clear evidence that methylation levels for P16(INK4A), $M L H 1$ and $D A P K$ also increased with age in the normal colonic mucosa (Figure 2A). Moreover, although the strongest associations between high methylation levels and female gender were observed for $E R \alpha$ and $M Y O D$, a similar trend was apparent for all other genes investigated with the exception of APC (Figure 2B). These results argue against a simple classification of $\mathrm{CpG}$ islands into Type A or Type $\mathrm{C}$ and suggest instead that differences in their methylation levels in normal colonic tissue are quantitative rather than qualitative.

The second major finding of this study was that promoter methylation levels in normal colonic mucosa showed no apparent associations with site in the large bowel. This was an unexpected observation because tumour methylation levels for most of the genes examined here are known to be much higher in cancers arising in the proximal colon compared to those from the distal colon or rectum (Toyota et al, 1999; Hawkins et al, 2002; Van

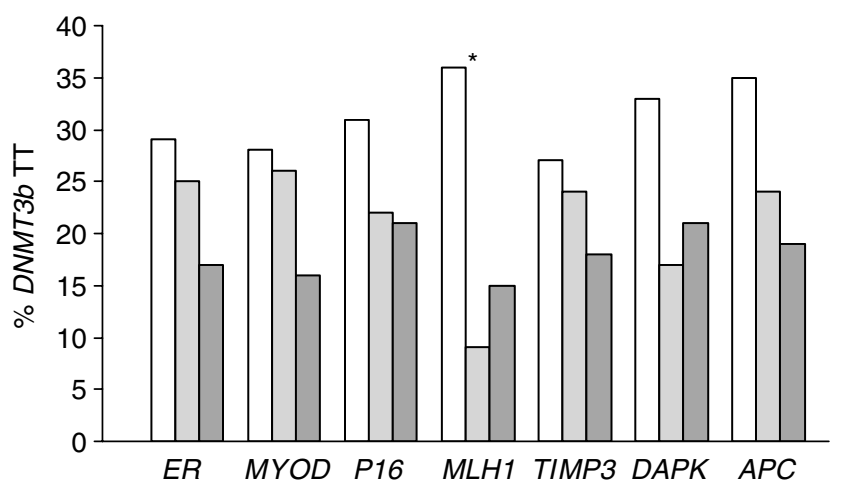

Figure 4 Colorectal cancer patients with no detectable methylation in normal colon tissue were more often homozygous for the DNMT3b C46359T variant compared to patients with high levels of methylation. Although not reaching statistical significance, this trend was seen for all seven genes investigated. No detectable methylation (open bars), low methylation (light bars) and high methylation (dark bars) groups are shown. *P $<0.1$.

Rijnsoever et al, 2002). We caution, however, that additional studies involving more precise sampling of normal colonic mucosa from individuals without cancer are required before concluding that there are no site-related differences in the CpG-island methylation levels of this tissue.

The third major finding of the current study was the presence of relatively high methylation levels in the normal colonic tissues of patients with $\mathrm{MSI}^{+}$and CIMP ${ }^{+}$tumours (Figure 3 ). This was particularly apparent for P16(INK4A), MLH1, TIMP3 and DAPK but was seen for all genes examined. Elevated MLH1 methylation has previously been reported in the normal gastric epithelia of patients with stomach cancer compared to noncancer individuals (Waki et al, 2002). Increased MGMT methylation in the normal mucosa of patients with colon cancers showing MGMT methylation was also reported recently (Shen et al, 2005). Together, these observations suggest that methylation levels in the normal colonic mucosa could serve as markers of risk for the development of CRC and in particular for the closely related $\mathrm{MSI}^{+} / \mathrm{CIMP}^{+}$subgroup. Longitudinal studies performed on individuals at high risk of developing $\mathrm{CIMP}^{+} \mathrm{CRC}$ will be required to test this hypothesis.

Older age and female gender (Figures 1 and 2) are generally associated with higher methylation levels for most CpG islands in normal colonic mucosa. However, it is clear that considerable interindividual variation occurs in the methylation level for this tissue, with some young patients showing relatively high values (Figure 1). Genetic, dietary and environmental factors are therefore also likely to be important in determining CpG-island methylation levels. Dietary information was not available for this patient series and hence could not be investigated. We did, however, investigate several common, functional polymorphisms in genes known to play major roles in methyl group metabolism, with only the DNMT3b C46359T variant found to be associated with methylation levels in normal mucosa (Figure 4). Although the sample size was relatively small, all seven $C p G$ islands investigated in this study showed less methylation in DNMT3b TT homozygous individuals compared to those with the CC/CT genotype. DNMT3b mediates de novo DNA methylation, with the $\mathrm{C} / \mathrm{T}$ transition polymorphism postulated to increase in vitro transcriptional activity by $30 \%$ (Shen et al, 2002). The lower methylation level observed here for DNMT3b TT homozygotes is therefore contrary to expectations and this gene could influence the level of global DNA methylation independently of the hypermethylation of $\mathrm{CpG}$ islands in promoter regions. Additional studies performed on large cohorts of noncancer individuals and incorporating dietary information are required to confirm the novel association reported 
here between DNMT3b genotype and CpG-island methylation levels in normal colonic mucosa.

Although the DNMT3b C46359T variant appears to be associated with $\mathrm{CpG}$-island methylation levels in the normal colonic mucosa (Figure 4), we have not determined whether this polymorphism also confers a risk for the development of $\mathrm{CIMP}^{+}$CRC. The contribution of genetic factors to the development of $\mathrm{CIMP}^{+}$is controversial, with some workers reporting an association between family history of CRC and CIMP ${ }^{+}$(Frazier et al, 2003; Young et al, 2005), but not others (Ward et al, 2004). Functional polymorphisms in methyl group metabolism and DNA methylation genes are clearly interesting candidates for further study and are currently being investigated in large cohorts of well-defined $\mathrm{CIMP}^{+}$tumours.

In conclusion, methylation levels for most $\mathrm{CpG}$ islands in normal colonic mucosa increase with age and are higher in female subjects. Unlike colorectal tumours, methylation levels in the

\section{REFERENCES}

Ahuja N, Li Q, Mohan AL, Baylin SB, Issa JP (1998) Aging and DNA methylation in colorectal mucosa and cancer. Cancer Res 58: 5489-5494

Bariol C, Suter C, Cheong K, Ku SL, Meagher A, Hawkins N, Ward R (2003) The relationship between hypomethylation and $\mathrm{CpG}$ island methylation in colorectal neoplasia. Am J Pathol 162: 1361 -1371

Baylin SB, Herman JG, Graff JR, Vertino PM, Issa JP (1998) Alterations in DNA methylation: a fundamental aspect of neoplasia. Adv Cancer Res 72: $141-196$

Chen J, Kyte C, Valcin M, Chan W, Wetmur JG, Selhub J, Hunter DJ, Ma J (2004) Polymorphisms in the one-carbon metabolic pathway, plasma folate levels and colorectal cancer in a prospective study. Int $J$ Cancer 110: $617-620$

Choi SW, Mason JB (2002) Folate status: effects on pathways of colorectal carcinogenesis. J Nutr 132: 2413S-2418S

Eads CA, Lord RV, Wickramasinghe K, Kurumboor SK, Bernstein L, Peters JH, DeMeester SR, DeMeester TR, Skinner KA, Laird PW (2001) Epigenetic patterns in the progression of esophageal adenocarcinoma. Cancer Res 61: $3410-3418$

Feinberg AP, Vogelstein B (1983) Hypomethylation distinguishes genes of some human cancers from their normal counterparts. Nature 301: $89-92$

Frazier ML, Xi L, Zong J, Viscofsky N, Rashid A, Wu EF, Lynch PM, Amos CI, Issa JP (2003) Association of the CpG island methylator phenotype with family history of cancer in patients with colorectal cancer. Cancer Res 63: $4805-4808$

Frigola J, Sole X, Paz MF, Moreno V, Esteller M, Capella G, Peinado MA (2005) Differential DNA hypermethylation and hypomethylation signatures in colorectal cancer. Hum Mol Genet 14: 319-326

Friso S, Choi SW, Girelli D, Mason JB, Dolnikowski GG, Bagley PJ, Olivieri O, Jacques PF, Rosenberg IH, Corrocher R, Selhub J (2002) A common mutation in the 5,10-methylenetetrahydrofolate reductase gene affects genomic DNA methylation through an interaction with folate status. Proc Natl Acad Sci USA 99: 5606-5611

Grieu F, Joseph D, Norman P, Iacopetta B (2004) Development of a rapid genotyping method for single nucleotide polymorphisms and its application in cancer studies. Oncol Rep 11: 501-504

Hawkins N, Norrie M, Cheong K, Mokany E, Ku SL, Meagher A, O'Connor $\mathrm{T}$, Ward R (2002) CpG island methylation in sporadic colorectal cancers and its relationship to microsatellite instability. Gastroenterology 122: $1376-1387$

Ishiguro K, Kawakami K, Maeda K, Ishida Y, Omura K, Watanabe G (2003) Microsatellite instability in gastric cancer is closely associated with hMLH1 hypermethylation at the proximal region of the promoter. Int $J$ Mol Med 12: 603-608

Issa JP (1999) Aging, DNA methylation and cancer. Crit Rev Oncol Hematol 32: $31-43$

Issa JP, Ottaviano YL, Celano P, Hamilton SR, Davidson NE, Baylin SB (1994) Methylation of the oestrogen receptor CpG island links ageing and neoplasia in human colon. Nat Genet 7: 536-540

Kambara T, Simms LA, Whitehall VL, Spring KJ, Wynter CV, Walsh MD, Barker MA, Arnold S, McGivern A, Matsubara N, Tanaka N, Higuchi T, Young J, Jass JR, Leggett BA (2004) BRAF mutation is associated with normal mucosa do not vary according to anatomical site in the large bowel. In addition to age and gender, a common genetic variant in the DNA methyltransferase gene DNMT3b also appears to influence CpG-island methylation levels in normal colonic mucosa. The methylation levels of several genes in normal colonic mucosa were associated with the presence of $\mathrm{MSI}^{+}$and $\mathrm{CIMP}^{+}$ tumours and could thus serve as molecular-based markers of risk for the development of this CRC subgroup.

\section{ACKNOWLEDGEMENTS}

This work was funded by a Grant-in-Aid for Scientific Research on Priority Areas from the Ministry of Education, Culture, Sports, Science and Technology of Japan.
DNA methylation in serrated polyps and cancers of the colorectum. Gut 53: $1137-1144$

Kane MF, Loda M, Gaida GM, Lipman J, Mishra R, Goldman H, Jessup JM, Kolodner R (1997) Methylation of the hMLH1 promoter correlates with lack of expression of hMLH1 in sporadic colon tumours and mismatch repair-defective human tumour cell lines. Cancer Res 57: 808-811

Kawakami K, Ruszkiewicz A, Bennett G, Moore J, Watanabe G, Iacopetta B (2003) The folate pool in colorectal cancers is associated with DNA hypermethylation and with a polymorphism in methylenetetrahydrofolate reductase. Clin Cancer Res 9: 5860-5865

Kawakami K, Watanabe G (2003) Identification and functional analysis of single nucleotide polymorphism in the tandem repeat sequence of thymidylate synthase gene. Cancer Res 63: 6004-6007

Kim YI (2004) Folate and DNA methylation: a mechanistic link between folate deficiency and colorectal cancer? Cancer Epidemiol Biomarkers Prev 13: $511-519$

Merlo A, Herman JG, Mao L, Lee DJ, Gabrielson E, Burger PC, Baylin SB, Sidransky D (1995) $5^{\prime}$ CpG island methylation is associated with transcriptional silencing of the tumour suppressor p16/CDKN2/MTS1 in human cancers. Nat Med 1: 686-692

Nakagawa H, Nuovo GJ, Zervos EE, Martin EW, Salovaara R, Aaltonen LA, de la Chapelle A (2001) Age-related hypermethylation of the 5' region of MLH1 in normal colonic mucosa is associated with microsatelliteunstable colorectal cancer development. Cancer Res 61: 6991-6995

Paz MF, Avila S, Fraga MF, Pollan M, Capella G, Peinado MA, SanchezCespedes M, Herman JG, Esteller M (2002) Germ-line variants in methylgroup metabolism genes and susceptibility to DNA methylation in normal tissues and human primary tumours. Cancer Res 62: 4519-4524

Rashid A, Issa JP (2004) CpG island methylation in gastroenterologic neoplasia: a maturing field. Gastroenterology 127: 1578-1588

Ruszkiewicz A, Bennett G, Moore J, Manavis J, Rudzki B, Shen L, Suthers G (2002) Correlation of mismatch repair gene immunohistochemistry and microsatellite instability status in HNPCC-associated tumours. Pathology 34: $541-547$

Samowitz WS, Albertsen H, Herrick J, Levin TR, Sweeney C, Murtaugh MA, Wolff RK, Slattery ML (2005a) Evaluation of a large, population-based sample supports a $\mathrm{CpG}$ island methylator phenotype in colon cancer. Gastroenterology 129: 837-845

Samowitz WS, Sweeney C, Herrick J, Albertsen H, Levin TR, Murtaugh MA, Wolff RK, Slattery ML (2005b) Poor survival associated with the BRAF V600E mutation in microsatellite-stable colon cancers. Cancer Res 65: 6063-6069

Sharp L, Little J (2004) Polymorphisms in genes involved in folate metabolism and colorectal neoplasia: a HuGE review. Am J Epidemiol 159: $423-443$

Shen H, Wang L, Spitz MR, Hong WK, Mao L, Wei Q (2002) A novel polymorphism in human cytosine DNA-methyltransferase-3B promoter is associated with an increased risk of lung cancer. Cancer Res 62: $4992-4995$

Shen L, Kondo Y, Rosner GL, Xiao L, Hernandez NS, Vilaythong J, Houlihan PS, Krouse RS, Prasad AR, Einspahr JG, Buckmeier J, Alberts DS, Hamilton SR, Issa JP (2005) MGMT promoter methylation and field defect in sporadic colorectal cancer. J Natl Cancer Inst 97: 1330 - 1338 
DNA hypermethylation in colonic mucosa

K Kawakami et al

Stern LL, Mason JB, Selhub J, Choi SW (2000) Genomic DNA hypomethylation, a characteristic of most cancers, is present in peripheral leukocytes of individuals who are homozygous for the C677T polymorphism in the methylenetetrahydrofolate reductase gene. Cancer Epidemiol Biomarkers Prev 9: 849-853

Toyota M, Ahuja N, Ohe-Toyota M, Herman JG, Baylin SB, Issa JP (1999) CpG island methylator phenotype in colorectal cancer. Proc Natl Acad Sci USA 96: $8681-8686$

Van Rijnsoever M, Elsaleh H, Joseph D, McCaul K, Iacopetta B (2003) CpG island methylator phenotype is an independent predictor of survival benefit from 5-fluorouracil in stage III colorectal cancer. Clin Cancer Res 9: $2898-2903$

Van Rijnsoever M, Grieu F, Elsaleh H, Joseph D, Iacopetta B (2002) Characterisation of colorectal cancers showing hypermethylation at multiple CpG islands. Gut 51: 797-802

Waki T, Tamura G, Tsuchiya T, Sato K, Nishizuka S, Motoyama T (2002) Promoter methylation status of E-cadherin, hMLH1, and p16 genes in non-neoplastic gastric epithelia. Am J Pathol 161: 399-403
Ward RL, Cheong K, Ku SL, Meagher A, O’Connor T, Hawkins NJ (2003) Adverse prognostic effect of methylation in colorectal cancer is reversed by microsatellite instability. J Clin Oncol 21: 3729-3736

Ward RL, Williams R, Law M, Hawkins NJ (2004) The CpG island methylator phenotype is not associated with a personal or family history of cancer. Cancer Res 64: 7618-7621

Whitehall VL, Wynter CV, Walsh MD, Simms LA, Purdie D, Pandeya N, Young J, Meltzer SJ, Leggett BA, Jass JR (2002) Morphological and molecular heterogeneity within nonmicrosatellite instability-high colorectal cancer. Cancer Res 62: 6011-6014

Yamashita K, Dai T, Dai Y, Yamamoto F, Perucho M (2003) Genetics supersedes epigenetics in colon cancer phenotype. Cancer Cell 4: 121-131

Young J, Barker MA, Simms LA, Walsh MD, Biden KG, Buchanan D, Buttenshaw R, Whitehall VL, Arnold S, Jackson L, Kambara T, Spring KJ, Jenkins MA, Walker GJ, Hopper JL, Leggett BA, Jass JR (2005) Evidence for BRAF mutation and variable levels of microsatellite instability in a syndrome of familial colorectal cancer. Clin Gastroenterol Hepatol 3: $254-263$ 